\title{
Overview of damage assessment of structures
}

\author{
Pritam Hait, Arjun Sil* and Satyabrata Choudhury
}

Department of Civil Engineering, National Institute of Technology, Silchar 788 010, India

\begin{abstract}
Different available analytical and experimental methodologies of local and global damage index (LDI and GDI) determination for bridges and buildings along with their mathematical expression are reviewed in this article. In the literature, impact of seismic loading and material deterioration due to ageing effects is the main focus to study the performance. Case studies for assessment of bridges and buildings are appended here to understand variation of damage index (DI) for various levels of seismicity. The utility of the proposed methods has been discussed in this case study. This article also includes progressive development, limitations and directions of future research on damage assessment of structures. Based on the extensive literature review, the authors have critically analysed the pros and cons of the available methods. However, time-dependent damage assessment, damage estimation for various structural and non-structural components using different materials, variation of damage for different configurations of structures, and deterioration of roads and bridges are the probable future scope for research. In future, damage-based design considering multiple response parameters along with uncertain load characteristics such as seismic load, wind load, blast load, floods and accidental load could be considered to select allowable damage of structures that would help to understand and ensure the timedependent safety, progressive phases of collapse and serviceability with high reliability satisfying smart structural requirements.
\end{abstract}

Keywords: Bridges and buildings, damage index, loss assessment, seismicity.

DAMAGE to structures is mainly caused by different environmental factors and ageing. Over the years various methods have been used for damage assessment. In this article, an overview of damage assessment is provided. In 1921, Griffith ${ }^{1}$ had introduced fracture mechanics for brittle materials, but practically it has been mostly applied to metallic materials. Kaplan ${ }^{2}$ had implemented fracture mechanics for concrete. However, several researchers have shown interest in this approach and excavated this area with proficiency.

Damage assessment of a building could be easily done with several damage indices (DIs). DI of the structure could be determined either by balancing, demand and

*For correspondence. (e-mail: silarjun@gmail.com) capacity of the structure, or by degradation of some structural property ${ }^{3}$. In Lee and Fenves plastic damage model, DI was estimated from nonlinear regression of experimental column test data, concentrating on local tensile damage variables such as drift ratio and moment ${ }^{4}$. Another DI was proposed based on cumulative member ductility considering limiting rotation capacity for steel, reinforced concrete (RC) columns, composite beams and composite steel-concrete connection sub-assemblies ${ }^{5}$. Damage probability matrices are useful for decisive criteria for strengthening strategies and repairing buildings; Monte Carlo simulation with building strength parameters and ground motions are the variables for it ${ }^{6}$. DI has been determined from the pushover curve containing initial and final stiffness ${ }^{7}$. Damage could be assessed from the relationship between modal parameters-based GDI and local stiffness degradation along with the ageing effect on structures ${ }^{8}$. Further, seismic vulnerability of damaged and undamaged RC bare frames, RC buildings with infill wall considering in-plane behaviour, and combined in-plane and out-of-plane nonlinear behaviour examined under main seismic shock as well as aftershock events ${ }^{9}$. A damage curve was derived with the decrease of bending stiffness at the fractured section and DI estimated by strain responses of steel beams for pre- and post-earthquakes ${ }^{10}$. Structural damage was presented by flexibility matrices with changes of modal parameters (modal damping, frequency and mode shapes) $)^{11}$. However, irrespective of structure type and material, the ratio between initial resistance and reduced resistance capacity was calculated as general DI ${ }^{12}$. Plastic damage of concrete with thermodynamics laws depending on continuum damage mechanics theory was applied on fibre RC beam column simulated in ABAQUS ${ }^{13}$. Global damage index (GDI) of RC structure was estimated considering pseudo plastic hinges ${ }^{14}$. Seismic damage of RC members for shear-flexure interaction in inelastic range was analysed, which showed a sound relationship between finite element model and experimental results ${ }^{15}$. A structural DI was calculated with curvature and stiffness ${ }^{16}$. Inclusion of correlative term 'stiffness' in the Park-Ang DI in Bayesian framework was introduced ${ }^{17}$. Influence of different durations of aftershock was measured in terms of degradation of strength and stiffness of a structure termed as damage ratio ${ }^{18}$. Structural damage was accurately detected using modified Cornwell indicator with genetic algorithm ${ }^{19}$. DI also depends on hysteretic energy dissipated by a structural member and a drift ratio of $76 \mathrm{RC}$ 
columns $^{20}$. Strain energy with various stiffness and ductility values, and dissipated energy with hysteretic cycles were linearly combined to estimate $\mathrm{DI}^{21}$. A normalized modal strain energy-based DI and teaching-learningbased algorithm were proposed to locate and measure the severity of damaged elements in truss model ${ }^{22}$. The ParkAng damage model was modified with biaxial effect to develop relationship between moment and rotation for effective determination of DI of RC pier $^{23}$. Threedimensional DI for 3D structures was proposed using bidirectional and torsional response effects ${ }^{24}$. To overcome non-convergence problems at its limits, the ParkAng damage model was modified by Jaing et al. ${ }^{25}$. Artificial neural network (ANN) was used as a prediction tool for function and pattern recognition problem to predict DI for RC framed structures considering interstorey drift $(\text { IDR })^{26}$. Demand of ground motion and capacity of structures are the two key factors to estimate structural DI. This estimation includes two sources of damage, viz. permanent deformation and cyclic loading effect when an earthquake occurs ${ }^{27}$. Local damage in flexural structural member was quantified as modal strain energy of a structure at different degradation stages ${ }^{28}$. Fuzzy logic system and Monte Carlo simulation were used for detection of damage in materials and uncertainty measurement found at significant problem for damage assessment of structure $^{29}$. Modal strain energy-based DI was proposed to locate and calculate damage using $\mathrm{ANN}^{30}$. Different modal parameters such as natural frequency, damping factor, modal participation factor and mode shape of a structure were used to calculate storey $\mathrm{DI}^{31,32}$. However, DI determination based on building construction cost per square metre, replacement ratio (approximate cost of replacing a median-sized domestic building) was undertaken by Blong ${ }^{33}$. Time-domain DI, viz. normalized correlation moment (NCM) holds statistical features of the waveform $^{34}$. Dynamic characteristics of structures in various fields such as forced or ambient vibration methods were compiled to rapidly and accurately assess $\mathrm{DI}^{35}$.

Further, fatigue damage evaluation in welded joints in railway steel bridges was proposed to check the effectiveness of the critical plane approach ${ }^{36}$. A static damage detection algorithm was used to measure damage in bridges considering permanent load (self-weight), temperature effect and time-dependent deterioration ${ }^{37}$. However, finite element method was used for damage assessment of bridges incorporating water level, flow velocity and scouring depth ${ }^{38}$. The fatigue damage assessment of bridges was performed combining finite element modelling and modal superposition method using fracture mechanics and crack propagation laws ${ }^{39}$. Fatigue damage assessment of bridges was performed to determine the progressive deterioration and nonlinear effects of fatigue damage accumulation under dynamic vehicle loads $\mathrm{s}^{40}$. However, a rapid seismic damage estimation method of steel plate girder bridges has been proposed for seismic risk analysis without significant loss of time and effort. The approach could be applied for making macro-level decisions for estimation of seismic damage of bridges ${ }^{41}$. A simple equation as a function of intensity measure (IM) was proposed for seismic damage assessment of motor-way bridges using finite element method ${ }^{42}$.

\section{Classification of damage index for buildings}

Several DI estimation procedures have been proposed on various structures by researchers in the past. As shown in Supplementary Table 1, a comprehensive study has been performed on buildings.

\section{Classification of damage index of bridges}

The damage assessment of bridges is different from other structures as they undergo random vehicle load causing fatigue deterioration. Classification of DIs for bridges are shown in Supplementary Table 2.

\section{Limitations of available methods}

Researchers have developed several methods to determine DI of structures, both numerically and experimentally over the past decades. Evaluation approaches are being developed to maximize the accuracy. Table 1 shows possible advantages and disadvantages of the available damage estimation methods.

However, structural damage mainly occurs in two phases during the service life of any structure; the first phase is due to load events such as seismic load, wind load, any accidental load, and weathering effects at the initial phases, whereas the second phase is initiated at a later time, which results in the deterioration of material as well as structural strength. The material deterioration has been determined in many ways over the past decades. However, load event estimated considering structural response parameters such as IDR, joint rotation and stiffness degradation individually $3,7,10,13$. These parameters alone cannot measure the reliability of damage index of structures. Nowadays, the combined effects of multiple response parameters are considered, which have improved the damage estimation procedure ${ }^{4-6,8,11,43}$. However, all the methods have limited application and cannot be applied for all types of structure. Also, there are neither any codes nor guidelines available for such assessment. Indeed, damage mainly depends upon load and resisting capacity of a structure. As the seismic event is uncertain in nature, therefore intensity and frequency of occurrence of load event should be considered probabilistically along with multiple influential parameters ${ }^{43}$. A guideline could be prescribed considering different types of probable load impact on different types of structures 
Table 1. Summary of some damage indices techniques

\begin{tabular}{|c|c|c|}
\hline Author & Virtue & Limitations \\
\hline Park and Ang & Considered both deformation and hysteretic energy & $\begin{array}{l}\text { Torsional effect was not considered } \\
\text { High computational time for large structure }\end{array}$ \\
\hline Bracci et al. & Based on curvature and stiffness & Inelastic behaviour was not considered \\
\hline Pandey et al. & Curvature mode shape determines location and size of damage & Extensive work required for large scale study \\
\hline Blong & Damage has been determined by cost analysis & Structural response parameters were ignored \\
\hline Jeong and Elnashai & DI calculated with torsional effect and geometric irregularities & $\begin{array}{l}\text { Applicability in high rise structure is not } \\
\text { mentioned }\end{array}$ \\
\hline Huang et al. & $\begin{array}{l}\text { Park-Ang DI was modified and proposed method varies } \\
\text { between } 0 \text { and } 1 \text { and limited scatter }\end{array}$ & Biaxial effect was not considered \\
\hline Diaz et al. & $\begin{array}{l}\text { DI was estimated with variation of stiffness, ductility and } \\
\text { dissipated hysteretic energy }\end{array}$ & $\begin{array}{l}\text { Torsion and bidirectional-moment effect was } \\
\text { ignored. }\end{array}$ \\
\hline
\end{tabular}

Table 2. Proposed damage states by researchers

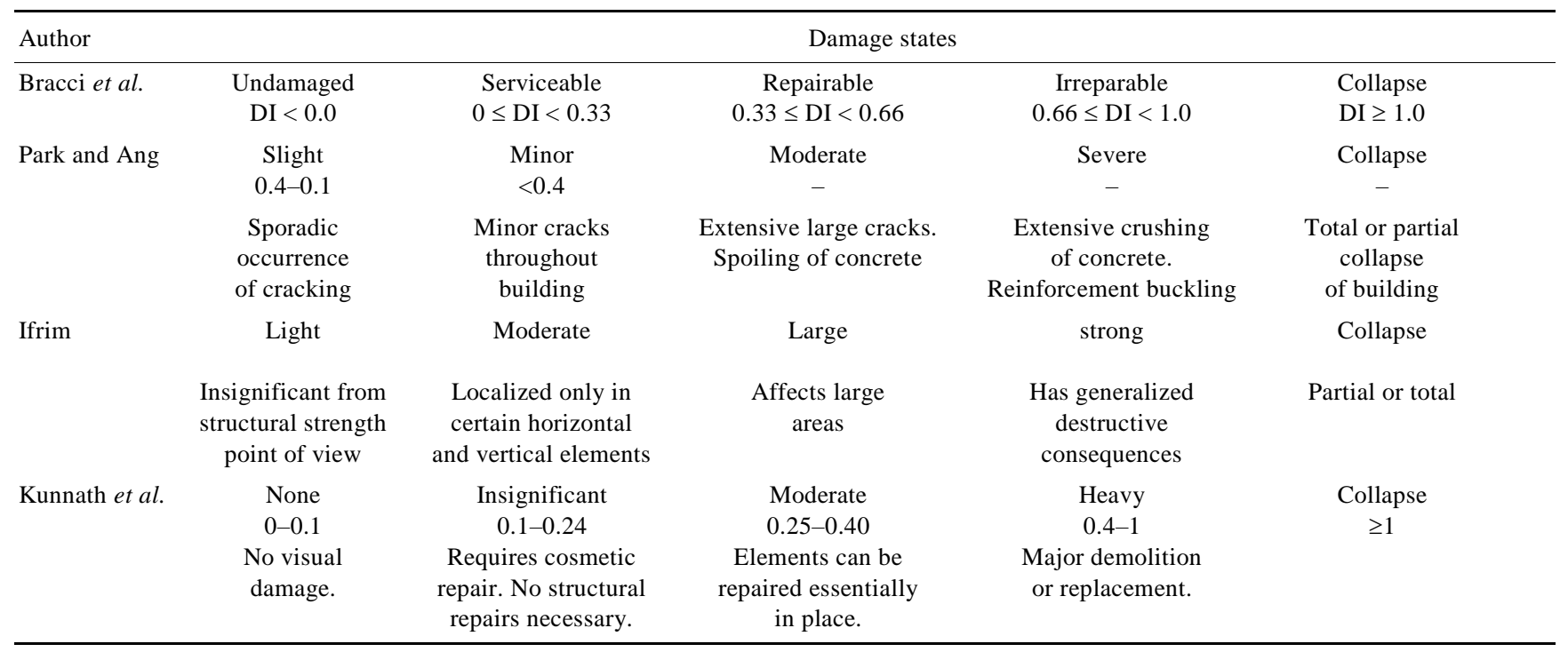

for damage-based design (DBD). Fragility curve for all performance levels, i.e. immediate occupancy (IO), life safety (LS) and collapse prevention (CP) in terms of damage would provide a new design approach for DBD of a structure.

Although several studies have been performed to assess damage due to seismic load, wind load, floods, fatigue deterioration and any other accidental load events, an extensive study is essential for damage assessment of bridge structures because the available damage detection methods are either applicable on a portion or on specific kinds of bridges. Different loads have different impacts on different types of bridges. Therefore classification and assessment are required according to the configuration and load type, including uncertainty. Table 2 gives a calibration of different damage states.

\section{Case study}

There are several methods available for estimating DI considering various response parameters proposed by several researchers. Among them, capacity and response spectra-based DI (eq. 1) is one of the latest methods proposed by Diaz et al. ${ }^{21}$ Strain energy and dissipated hysteretic energy were combined to estimate DI of a structure in the above-mentioned study as

$$
\mathrm{DI}_{\mathrm{EC}}(\delta)=\eta \mathrm{E}_{\mathrm{SO}}(\delta)_{\mathrm{NN}}+(1-\eta) \mathrm{E}_{\mathrm{D}}(\delta)_{\mathrm{NN}},
$$

where $\operatorname{DI}_{\mathrm{EC}}(\delta)$ is the energy capacity DI with respect to roof displacement, $\eta$ the calibration factor in the energy capacity DI (best value is 0.62$), \mathrm{E}_{\mathrm{SO}}(\delta)_{\mathrm{NN}}$ the normalized strain energy with respect to roof displacement, $\mathrm{E}_{\mathrm{D}}(\delta)_{\mathrm{NN}}$ the normalized energy dissipated with respect to roof displacement, $\mathrm{DI}_{\mathrm{PA}}(\delta)$ the Park-Ang DI with respect to roof displacement, $\mathrm{DI}_{\mathrm{PA}}$ (PGA) the Park-Ang DI with respect to peak ground acceleration (PGA) and $\mathrm{DI}_{\mathrm{EC}}(\mathrm{PGA})$ is the energy capacity DI with respect to PGA.

The proposed method was compared with the ParkAng DI, which was well-fitted by a combination of $38 \%$ of $\mathrm{E}_{\mathrm{D}}(\delta)_{\mathrm{NN}}$ function and $62 \%$ of $\mathrm{E}_{\mathrm{SO}}(\delta)_{\mathrm{NN}}$ function (Figure 1$)^{21}$. Diaz et al. ${ }^{21}$ concluded that this method could be 

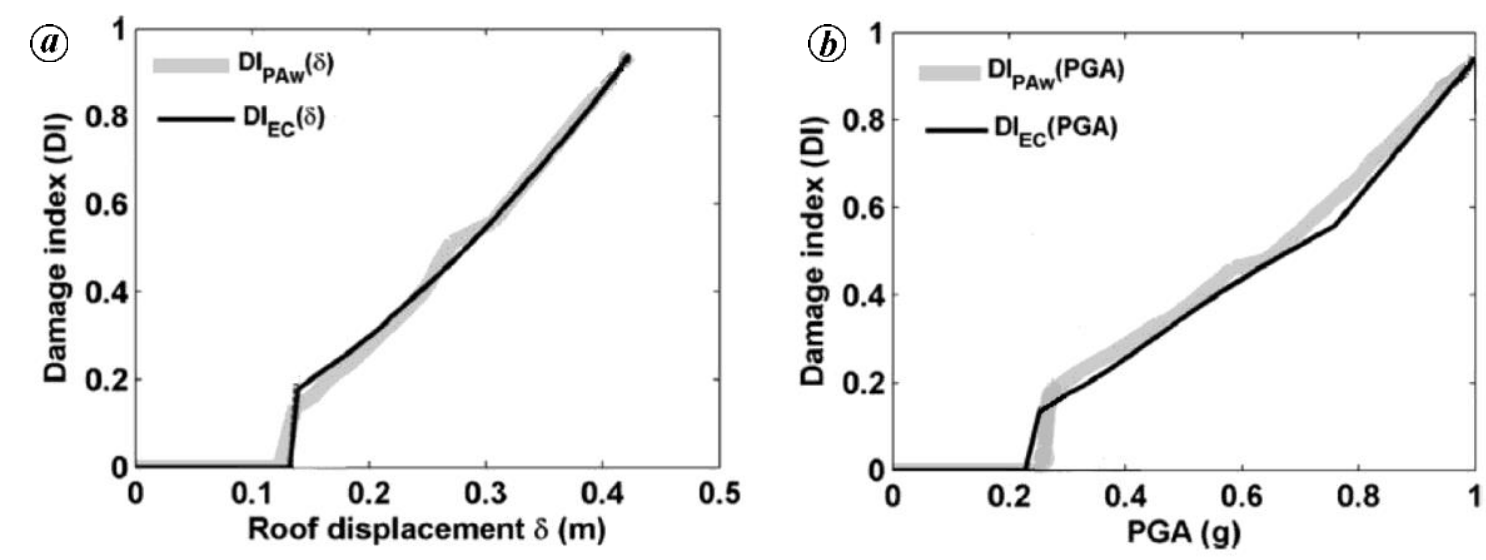

Figure 1. Comparison between energy capacity damage index (DI) and Park-Ang DI with respect to $(\boldsymbol{a})$ displacement $\left(D I_{\mathrm{PA}}(\delta)\right.$ and $\left.D I_{\mathrm{EC}}(\delta)\right)$ and $(\boldsymbol{b})\left(D I_{\mathrm{PA}}(\mathrm{PGA})\right.$ and $\left.D I_{\mathrm{EC}}(\mathrm{PGA})\right)$ peak ground acceleration (PGA).
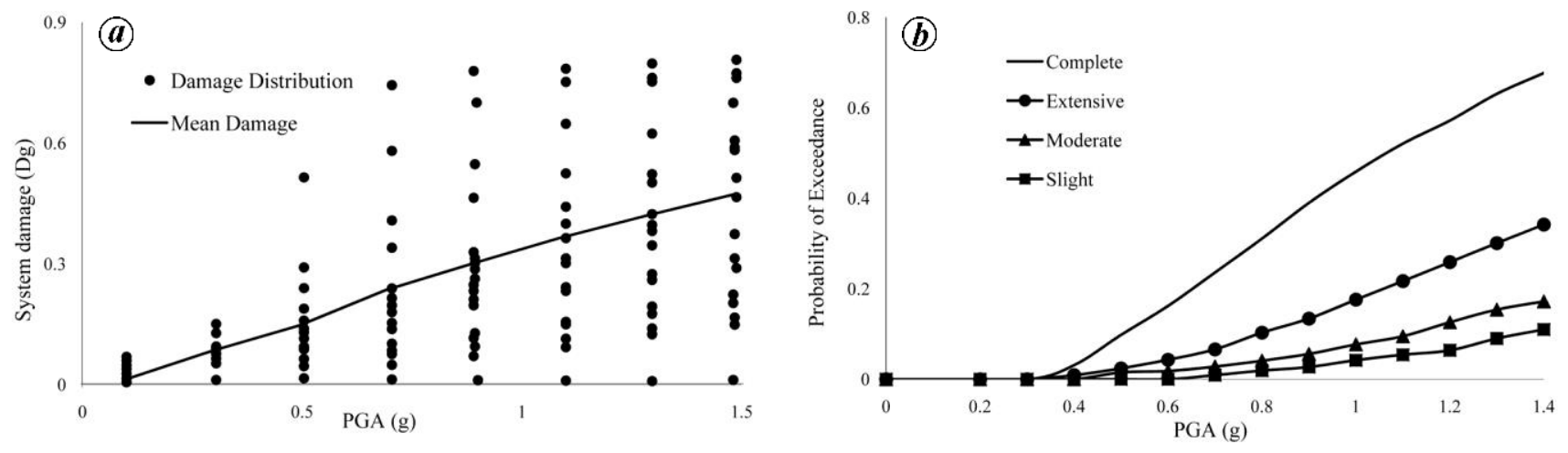

Figure 2. $\boldsymbol{a}$, Variation of system DI with PGA. $\boldsymbol{b}$, Fragility curve of the bridge.

an efficient tool to estimate seismic damage of structures, which reduces the computational time significantly.

Alternatively, a rapid seismic damage assessment of steel plate girder bridges was performed for seismic risk analysis by Park and Towashiraporn in 2014 (ref. 41). A simplified equation (eq. (2)) was proposed in this response-based modelling approach. Figure 2 shows the system damage $\left(D_{\mathrm{g}}\right)$ over PGA as well as fragility curve of the bridge $\mathrm{e}^{4}$.

$$
D_{G i, \mathrm{eq}}=\left\{\begin{array}{l}
I_{j}+0.25 \times \frac{D_{i, \mathrm{eq}}-D_{i, j}}{D_{i, j+1}-D_{i, j}} ; j=\text { none }, \\
\text { slght, moderate or extensive damage } \\
\frac{D_{i, e q}}{D_{i, j}} ; j=\text { complete damage }
\end{array}\right.
$$

where $D_{\mathrm{G} i}$ is the damage of component $i$ expressed in terms of generic damage measure, $D_{i, \text { eq }}$ the damage of component $i$ due to earthquake equation expressed in terms of its own damage measure and $D_{i, j}$ is the threshold response value corresponding to limit state $j$.

\section{Results and discussion}

In this article, the available case studies have reviewed/ examined and presented mainly the structural damage of buildings and bridges assessed by several methods along with their limitations. Indeed, damages are of different categories and types. Damage assessment of structural and non-structural elements is a major concerns considering nonlinearity. The other crucial concerns for society are discussed below.

\section{Damage assessment with different structural elements}

Shear wall, infill and soft storey have impact on structural damage, but are not considered to calculate DI. In future, damage assessment approaches must consider different types of damper, base isolation, cladding structure and effect of cold joints. For a precise analysis, uncertain and spatially variable seismic events must be categorized with zonal fragility curves for all performance levels as IO, LS and CP in terms of damage. 

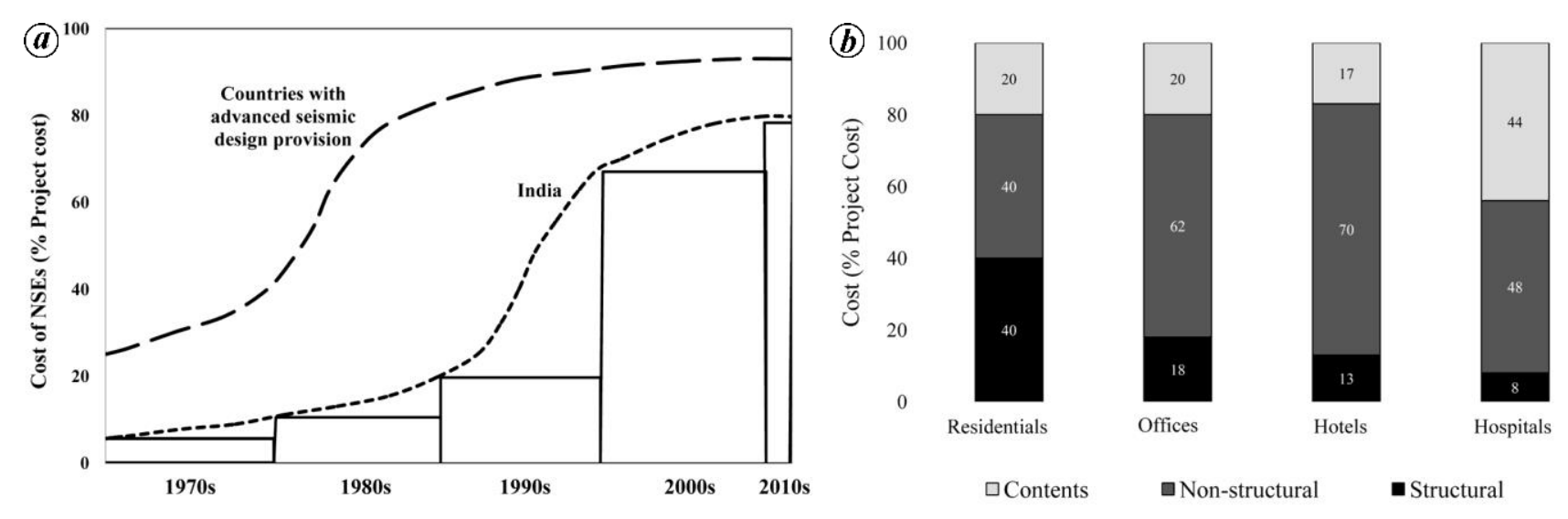

Figure 3. $\boldsymbol{a}$, Evolution trends in cost of NSEs used in building over the last four decades: in India and other seismic vulnerable countries. $\boldsymbol{b}$, Cost share of structure and NSEs in different types of building projects implemented in Japan and USA.

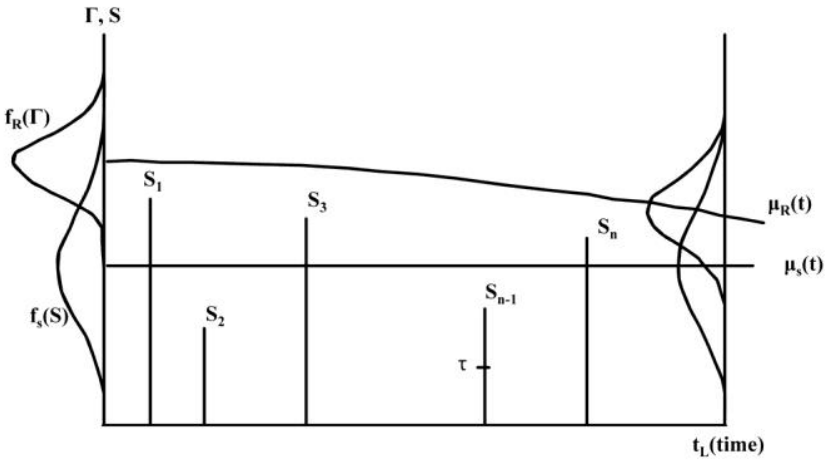

Figure 4. Representation of load process and degradation resistance.

\section{Non-structural damage}

Non-structural elements (NSEs) have a major impact on structures. NSEs like doors, windows, railings, false ceilings, water tanks, communication antennas, sewage pipelines, electric cables, refrigerators, etc. also play a vital role in damage. However, these have not been researched adequately. As shown in Figure 3, damages due to NSEs share the maximum cost ${ }^{44}$. This area needs attention while analysing design of a structure in earthquake prone regions and preventive action needs to be taken to minimize the damage or loss.

\section{Time-dependent assessment of damage}

Degradation of a structure depends on ageing, operating conditions, materials used, geometric shape, repeated loading, increased mean load and environmental factors. Chemical substances like sulphur and chloride, as well as humidity are the other causes of slow degradation of structures (Figure 4) ${ }^{45}$. Considerations of degradation of structures along with environmental impacts are not sufficiently explored or accounted. Different environmental factors versus degradation mechanism for hazard function are the future scope of research.

\section{Damage assessment of lifelines}

Lifelines are concern for society. Roads, highways, hospitals, underground communication systems, and communication towers are the important aspects to be taken care of.

\section{Materials used}

Fibre can be used to enhance shear, tension and bending strength in RC members. Economically feasible materials such as fibre-reinforced concrete, light weight and prestress concrete and wooden structures are being used at present. Utilization of different types of material is one of the recent research trends. Damage assessment of these materials is still unexplored.

\section{Geometry factors}

Plan aspect ratio, storey height, horizontal and vertical irregularities, tall structure, truss, dome and types of extension such as balcony are other factors to be considered for damage assessment.

\section{Damage assessment of bridges}

Researchers have been using several modal and nonmodal damage detection techniques. Local damage assessment such as deck slab, pier and abutment, crack and buckling in girder is still limited. It is essential to assess DI of an entire bridge. Damage due to fire, impact to bridge pier column, flood debris, flood scour, and barge impact are the probable future areas of research. 


\section{Conclusion}

In this article we present an overview of available damage assessment methods along with their mathematical expressions. Precedence and impediment of these approaches, progressive development and probable future research are explored. At present, performance-based design is of interest which includes deformation, drift and strength as performance criteria. With respect to reliability issues, DBD is a better approach as it consists of multiple response parameters which help calculate damage scenario accurately. In this context the Park-Ang DI method is a reliable index, although it requires high computational time. Nevertheless, researchers use this method because of its accuracy and ease of application compared to other modified methods.

From this review, we conclude that to ensure DBD, seismic zone-wise fragility curve must be prepared for all performance levels under uncertain loads such as seismic load, wind load, blast load, floods, and accidental load. A guideline is essential to prescribe $\mathrm{DBD}$, including fatigue analysis, assessment of structural elements and NSEs, lifelines, damage due to different types of composite materials, different structural configurations and areawise mapping of deterioration of both bridges and buildings due to ageing under different environmental conditions. Seismic zone-wise minimum requirement of design criteria must be included in the guidelines. In this design philosophy, a client can predefine the allowable damage to a structure under a particular load, which is a highlight of this approach.

1. Griffith, A. A., The phenomena of rupture and flow in solids. Philos. Trans. R. Soc. London, Ser. A, 1921, 221, 163-198.

2. Kaplan, M. F., Crack propagation and the fracture of concrete. J. Am. Concr. Inst., 1961, 58(11), 591-610.

3. Powel, G. H. and Allahabadi, R., Seismic damage prediction by deterministic method: concepts and procedures. Earthq. Eng. Struct. Dyn., 1988, 16, 719-734.

4. Kang, J. W. and Lee, J., A new DI for seismic fragility analysis of reinforced concrete columns. Struct. Eng. Mech., 2016, 60(5), 875-890.

5. Mehanny, S. S. F. and Deierlein, G. G., Seismic damage and collapse assessment of composite moment frames. J. Struct. Eng., ASCE, 2001, 127(9), 1045-1053.

6. Roufaiel, M. S. L. and Meyer, C., Reliability of concrete frames damaged by earthquakes. J. Struct. Eng., ASCE, 1987, 113(3), 445-457.

7. Ghobarah, A., Abou-elfath, H. and Biddah, A., Response based damage assessment of structures. Earthq. Eng. Struct. Dyn., 1999, 28, 79-104.

8. DiPasquale, E., Ju, J.-W., Askar, A. and Cakmak, A. S., Relation between global damage indices and local stiffness degradation. J. Struct. Eng., ASCE, 1990, 116(5), 1440-1456.

9. Furtado, A., Rodrigues, H., Varum, H. and Arêde, A., Main shock-aftershock damage assessment of in-filled RC structures. Eng. Struct., 2018, 175, 645-660.

10. Li, X., Kurata, M. and Nakashim, M., Simplified derivation of a damage curve for seismically induced beam fractures in steel moment-resisting frames. J. Struct. Eng., ASCE, 2016, 142(6), 04016019-1-04016019-13.

11. Pandey, A. K. and Biswas, M., Damage detection in structures using changes in flexibility. J. Sound Vib., 1994, 169(1), 3-17.

12. Colomboa, A. and Negrob, P., A damage index of generalized applicability. Eng. Struct., 2005, 27, 1164-1174.

13. Li, Z. H., Teng, J. and He, X. F., Seismic damage analysis model for RC structures based on concrete plastic damage model. In Proceedings of the Structures Congress, ASCE, Las Vegas, USA, 2011, pp. 2768-2779.

14. Amziane, S. and Dube, J. F., Global RC structural damage index based on the assessment of local material damage. J. Adv. Concr. Technol., 2008, 6(3), 459-468.

15. Mergos, P. E. Kappos, A. J., Seismic damage analysis including inelastic shear-flexure interaction. Bull. Earth. Eng., 2010, 8, 27-46.

16. Bracci, J. M., Reinhorn, Mander, J. B. and Kunnath, S. K., Deterministic model for seismic damage evaluation of reinforced concrete structures. NCEER Technical Report, 1989.

17. Yazdannejad, K. and Yazdani, A., Bayesian updating of the ParkAng damage index for RC frame buildings under near-fault ground motions. Sci. Iran., 2017, 25, 606-616.

18. Zhai, C.-H., Bao, X., Zheng, Z. and Wang, X.-Y., Impact of aftershocks on a post-mainshock damaged containment structure considering duration. Soil Dyn. Earthq. Eng., 2018, 115, 129-141.

19. Tiachacht, S., Bouazzouni, A., Khatir, S., Abdel Wahab, M., Behtani, A. and Capozucca, R., Damage assessment in structures using combination of a modified Cornwell indicator and genetic algorithm. Eng. Struct., 2018, 177, 421-430.

20. Rodriguez, M. E. and Padilla, D., A damage index for the seismic analysis of reinforced concrete members. Earthq. Eng. Struct. Dyn., 2009, 13, 364-383.

21. Diaz, S. A., Pujades, L. G., Barbat, A. H., Vargas, Y. F. and Hidalgo-Leiva, D. A., Energy damage index based on capacity and response spectra. Eng. Struct., 2017, 152, 424-436.

22. Dinh-Cong, D., Vo-Duy, T. and Nguyen-Thoi, T., Damage assessment in truss structures with limited sensors using a twostage method and model reduction. Appl. Soft Comput., 2018, 66, 264-277.

23. Guo, J., Wang, J. J., Li, Y., Zha, W. G. and Du, Y. L., Three dimensional extension for Park and Ang damage model. Structures, 2016, 7, 184-194.

24. Jeong, S.-H. and Elnashai, A. S., New three dimensional damage index for RC buildings with planar irregularities. J. Struct. Eng., ASCE, 2006, 132(9), 1482-1490.

25. Jaing, H. J., Chen, L. Z. and Chen, Q., Seismic damage assessment and performance levels of reinforced concrete members. Procedia Eng., 2011, 14, 939-945.

26. Morfidis, K. and Kostinakis, K., Approaches to the rapid seismic damage prediction of RC buildings using artificial neural networks. Eng. Struct., 2018, 165, 120-141.

27. Reinhorn, A., Kunnath, S., Bracci, J. and Mander, J., Normalized damage index for evaluation of buildings. Seismic Eng.: Res. Pract., ASCE, 1989, 507-516.

28. Eraky, A., Anwar, A. M., Saad, A. and Abdo, A., Damage detection of flexural structural systems using damage index methodexperimental approach. Alexandria Eng. J., 2015, 54, 497-507.

29. Chandrashekhar, M. and Ganguli, R., Damage assessment of composite plate structures with material and measurement uncertainty. Mech. Syst. Signal Process., 2016, 75, 75-93.

30. Tan, Z. X., Thambiratnam, D. P., Chan, T. H. T. and Abdu Razak, H., Detecting damage in steel beams using modal strain energy based damage index and artificial neural network. Eng. Failure Anal., 2017, 79, 253-262.

31. Wang, J.-F., Lin, C.-C. and Yen, S.-M., A story damage index of seismically-excited buildings based on modal frequency and mode shape. Eng. Struct., 2007, 29, 2143-2157. 
32. DiPasquale, E. and Cakmak, Detection and assessment of seismic structural damage. Technical report NCEER-87-0015, 1987.

33. Blong, R., A new damage index. Nat. Hazards, 2003, 30, 1-23.

34. Torkamani, S., Roy, S., Barkey, M. E., Sazonov, E., Burkett, S and Kotru, S., A novel damage index for damage identification using guided waves with application in laminated composites. Smart Mater. Struct., 2014, 23, 095015-1-095015-16.

35. Massumi, A. and Moshtagh, E., A new damage index for RC buildings based on variations of nonlinear fundamental period. Struct. Des. Tall Spec. Build., 2013, 22, 50-61.

36. Praveen, K. R., Mishra, S., Babu, P., Spagnoli, A. and Carpinteri, A., Multiaxial fatigue damage assessment of welded connections in railway steel bridge using critical plane approach. Proc. Eng., 2018, 213, 776-787.

37. Campos, J., Matos, E., Casas, J. R. and Figueiras, J., A new methodology for damage assessment of bridges through instrumentation: application to the Sorraia River Bridge. Struct. Infrastruct. Eng., 2005, 1(4), 239-252.

38. Sung, Y.-C. and Wang, C.-Y., A study on damage assessment of the scoured bridges. J. Chin. Inst. Eng., 2013, 36(8), 994-1007.

39. Albuquerque, C., Silva, A. L. L., de Jesus, A. M. P. and Calçada, R., An efficient methodology for fatigue damage assessment of bridge details using modal superposition of stress intensity factors. Int. J. Fatigue, 2015, 81, 61-77.

40. Zhang, W., Cai, C. S. and Pan, F., Nonlinear fatigue damage assessment of existing bridges considering progressively deteriorated road conditions. Eng. Struct., 2013, 56, 1922-1932.

41. Park, J. and Towashiraporn, P., Rapid seismic damage assessment of railway bridges using the response-surface statistical model. Struct. Saf., 2014, 47, 1-12.

42. Anastasopoulos, P. Ch., Anastasopoulos, Agalianos, A. and Sakellariadis, L., Simple method for real-time seismic damage assessment of bridges. Soil Dyn. Earthq. Eng., 2015, 78, 201-212.

43. Sil, A. and Longmailai, T., Drift reliability assessment of a four storey residential building under seismic loading considering multiple factors. J. Inst. Eng. (India), Ser. A, 2017, 8, 245-256.

44. Takahashi, N. and Shiohara, H., Life cycle economic loss due to seismic damage of non-structural elements. In Proceeding of the 13th World Conference on Earthquake Engineering, Vancouver, BC, Canada, 2004, Paper No. 203.
45. Mori, Y. and Ellingwood, B. R., Reliability-based service-life assessment of aging concrete structures. J. Struct. Eng., ASCE, 1993, 119(5), 1600-1621.

46. Huang, W., Qian, J. and Zhou, Z., Seismic damage assessment of steel reinforced concrete members by a modified Park-Ang model. J. Asian Archit. Build. Eng., 2016, 15(3), 605-611.

47. Pirasteh, S. and Li, J. and Attarzadeh, I., Implementation of the damage index approach for the rapid evaluation of earthquake resistant buildings. Earth Sci. Inform., 2015, 8, 751-758.

48. Park, Y.-J. and Ang, A. H. S., Mechanistic seismic damage model for reinforced concrete. J. Struct. Eng., ASCE, 1985, 111(4), 722739.

49. Guan, H. and Karbhari, V. M., Improved damage detection method based on element modal strain damage index using sparse measurement. J. Sound Vibr., 2008, 309, 465-494.

50. Banon, H., Biggs, J. M. and Irvine, H. M., Seismic damage in reinforced concrete frames. J. Struct. Eng., ASCE, 1981, 107(9), 1713-1729.

51. Gosain, N. K., Brown, R. H. and Jirsa, J. O., Shear requirements for load reversals on RC members. J. Struct. Eng., ASCE, 1977, 113(7), 1461-1476.

52. Jeong, G. D. and Iwan, W. D., The effect of earthquake duration on the damage of structures. Earthq. Eng. Struct. Dyn., 1988, 16, 1201-1211.

53. Stubbs, N., Kim, J.-T. and Farrar, C. R., Field verification of a nondestructive damage localization and severity estimation algorithm. In Proceedings of the 13th International Modal Analysis Conference, 1995, 2460, 210-218.

54. Koo, K.-Y., Lee, J.-J., Yun, C.-B. and Kim, J.-T., Damage detection in beam-like structures using deflections obtained by modal flexibility matrices. Adv. Sci. Technol., 2008, 56, 483-488.

55. Pandey, A. K., Biswas, M. and Samman, M. M., Damage detection from changes in curvature mode shapes. J. Sound Vib., 1991, 145(2), 321-332.

56. Ifrim, M., Dinamica structurilor şi inginerie seimică. Edit. Did. Şi Pedag. Bucureşti, 1984.

Received 16 April 2018; revised accepted 12 March 2019

doi: $10.18520 / \mathrm{cs} / \mathrm{v} 117 / \mathrm{i} 1 / 64-70$ 